\title{
Analysis of urban air pollution based on network observation
}

\author{
Anatoly A. Lezhenin ${ }^{1}$, Vladimir F. Raputa ${ }^{1}$ \\ ${ }^{1}$ Institute of Computational Mathematics and Mathematical Geophysics, Novosibirsk, Russia
}

\begin{abstract}
A joint analysis of cases of high monthly mean concentrations of benzo(a)pyrene measured at stationary stations of Roshydromet in the atmospheric air of the cities of Novosibirsk and Iskitim of the Novosibirsk region is carried out. The influence of meteorological conditions on pollution levels is investigated. Particular attention is paid to the analysis of observational data carried out in the winter months of 2018, for which high monthly mean concentrations of benzo(a)pyrene were recorded in both cities, reaching 15-20 maximum permissible concentrations. Correlation relationships were obtained between measurements at stations in the cities of Novosibirsk and Iskitim, which indicates the determining influence of meteorological conditions on pollution levels.
\end{abstract}

\section{Keywords}

Atmosphere, wind rose, pollution, control points, benzo(a)pyrene.

\section{Introduction}

Assessment of the state of air pollution in Russian cities is based on observational data obtained from stationary posts of the Roshydromet network. Data from stationary stations make it possible to assess the concentration fields of polluting impurities over the city territory $[1,2]$.

When forming a network of stations, it is necessary to represent the location of control posts, the unity of the program and the regularity of observations. When organizing a network, the results of preliminary experimental and theoretical studies are taken into account $[2,3,4]$. Monitoring is carried out using stationary, route and under-flare observation posts. Stationary observations are carried out in specially equipped pavilions. Mobile posts are usually used as a supplement to the stationary network, depending on the current air pollution conditions in certain areas of the city. It should also be noted that significant information can be obtained using natural tablets: soil, vegetation and snow cover $[5,6,7,8,9,10]$. In the future, the involvement of joint data from ground-based and satellite monitoring of snow cover makes it possible to detail the picture of pollution in urban areas [8,11, 12, 13, 14, 15].

Many Siberian cities are characterized by the presence of significant levels of benzo(a)pyrene (BP) concentrations during winter periods $[16,17]$. This is due to the higher volumes of fossil fuel combustion. Also, meteorological conditions have a certain influence. As a rule, high levels of pollution occur with weak winds $[2,4,17]$.

SDM-2021: All-Russian conference, August 24-27, 2021, Novosibirsk, Russia @lezhenin@ommfao.sscc.ru (A. A. Lezhenin); raputa@sscc.ru (V.F. Raputa) 
The aim of the study is to analyze the conditions for the formation of increased concentrations of impurities in the atmosphere of the city Novosibirsk and Iskitim.

\section{Objects and materials of research}

In 2018, Iskitim of the Novosibirsk Region was included in the list of settlements in Russia with a very high level of air pollution [18]. It should be noted that a significant part of the city's territory is located in the zone of high potential for atmospheric pollution (PZA) [17]. The city is located in a heterogeneous terrain. The difference in elevation in Iskitim reaches one hundred meters. The central part of the city is located in the valley of the Berd River. This part of the city is largely influenced by the microclimatic features of the area.

Regular BP measurements in Iskitim are carried out at one post in the northern part of the city. The main highway of the city (Sovetskaya st.) Passes nearby. The post is located at a distance of one kilometer from the high-rise pipes of the cement plant. Certain BP steps can occur as a result of emissions from boiler houses and the private sector using fossil fuels.

The highest concentrations are observed during winter periods. In the winter period of 2018, the average monthly BP concentration reached 15-20 maximum permissible concentrations (MPC) [18]. One MAC corresponds to $1 \mathrm{ng} / \mathrm{m}^{3}$. According to the city administration, additional sources of BP emissions did not appear on the territory of Iskitim in 2018. Presumably unfavorable meteorological conditions increased the accumulation of pollutants at the earth's surface.

The Iskitim meteorological station (WMO index 29730) is close to the air pollution observation point. This makes it possible to correctly analyze the processes of transport of pollutants from possible sources.

The city of Novosibirsk is a large industrial center of the West Siberian economic region. The city is located on the banks of the Ob River and is located in the zone of increased PZA. The climate of Novosibirsk is characterized as continental [19]. The main sources of air pollution are enterprises producing construction materials, metallurgy, heat and power engineering, and automobile transport. Industrial enterprises throughout the city are located in large complexes. In 2018, BP measurements were carried out at 10 posts in Novosibirsk. The average annual concentration of BP in 2018 was 2.4 MAC. However, it should be noted that at some posts of the city in the winter months the concentration of BP reached 15-20 MPC. At a number of other stations, it was comparatively small. As a result, there was a significant leveling of the average value of the BP concentration in the city. Taking into account the large area of Novosibirsk and the low density of observation posts, the use of arithmetic mean estimates of BP concentrations is not entirely correct.

For the analysis of meteorological conditions, the data of measurements at the station located near the city of Novosibirsk (WMO index 29638) were used. The results of monthly average measurements of BP at post No. 1 in Iskitim were compared with the results of measurements at post No. 21 in Novosibirsk. The choice of these posts is due to their proximity to major highways of the cities under consideration. Both posts are located on the "leeward" side of the motorways, are located in the directions of the prevailing drift of impurities from sources. 


\section{Results and discussions}

According to meteorological observations in the winter months of 2018, the average temperature was almost $1.5^{\circ} \mathrm{C}$ below the average climatic. Also, unfavorable meteorological conditions were recorded, in which there is an accumulation of pollutants at the surface of the earth, including BP. One of the main factors for increasing the concentration of impurities in the atmospheric air are weak winds and calm conditions.

Tables 1 and 2 provide information on the frequency of calm and BP concentrations for the cities of Novosibirsk and Iskitim in the winter periods of 2018, 2019.

From the analysis of the Tables 1 and 2, it follows that in February and December 2018, the highest BP concentrations were recorded both in Novosibirsk and Iskitim. In the same months, the frequency of calm was also high. A relatively moderate concentration of $\mathrm{BP}$ in both cities was in January 2018, with a lower percentage of calm conditions. In general, this trend is confirmed by the data of 2019. A noticeable excess of calm conditions in February 2019 at the Novosibirsk meteorological station could manifest itself indirectly on the value of the BP concentration at post No. 21 due to their mutual remoteness.

In Figures 1 and 2 for weather stations Novosibirsk and Iskitim show wind roses for the winter months of 2018. Figure 1, it follows that in the winter months of 2018, southerly winds prevailed in Novosibirsk. Figure 2 shows that southwestern winds prevailed for Iskitim at this time. This means that the observation posts in both cities were under the dominant influence of pollutant emissions from nearby highways. Comparison of the concentration levels of BP, given in Tables 1 and 2, does not allow revealing their explicit dependence on the prevailing wind direction.

In Figure 3 shows the correlation dependences between the monthly average BP concentrations for the cities of Novosibirsk and Iskitim in 2018, 2019. Analysis of Figure 3 indicates the presence of general statistical regularities in the formation of BP concentration levels for post No. 21 in Novosibirsk and post No. 1 in Iskitim. The high level of agreement can be explained

Table 1

Calm recurrence and BP concentrations at post No. 21 in Novosibirsk in the winter months of 2018, 2019.

\begin{tabular}{c|ccc|ccc}
\hline $\begin{array}{c}\text { Year } \\
\text { Month }\end{array}$ & January & February & December & January & February & December \\
\hline Calm recurrence, \% & 6 & 17 & 17 & 3 & 14 & 2 \\
BP concentration, $\mathrm{ng} / \mathrm{m}^{3}$ & 7.2 & 12.6 & 14.6 & 5.5 & 6.4 & 3.8 \\
\hline
\end{tabular}

\section{Table 2}

Calm recurrence and BP concentrations at post No. 1 in Iskitim in the winter months of 2018, 2019.

\begin{tabular}{c|cccc|ccc}
\hline $\begin{array}{c}\text { Year } \\
\text { Month }\end{array}$ & January & $\begin{array}{c}2018 \\
\text { February }\end{array}$ & December & January & February & December \\
\hline Calm recurrence, \% & 7 & 15 & 13 & 7 & 7 & 7 \\
BP concentration, $\mathrm{ng} / \mathrm{m}^{3}$ & 7.1 & 17.2 & 19.7 & 5.9 & 6.6 & 3.3 \\
\hline
\end{tabular}




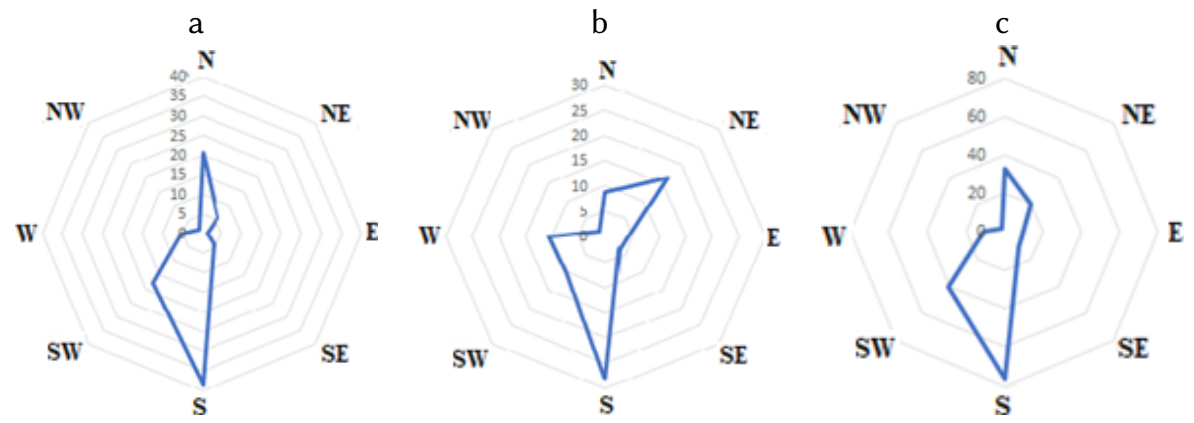

Figure 1: Frequency of wind directions (\%) at the Novosibirsk meteorological station for January (a), February (b) and December (c) 2018.

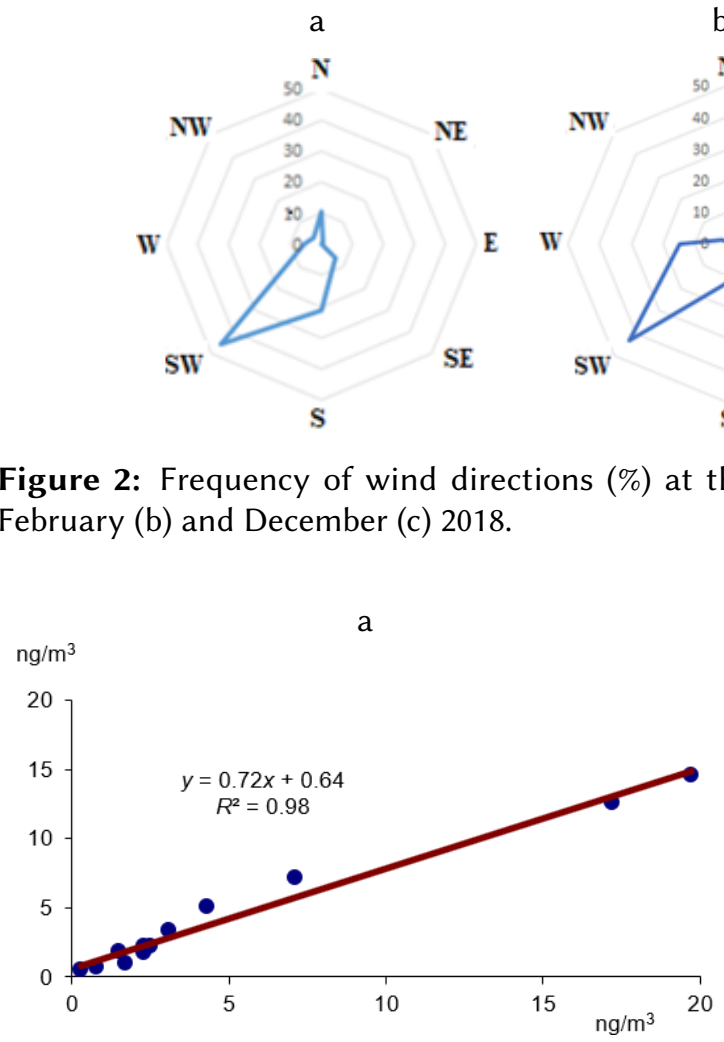

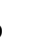

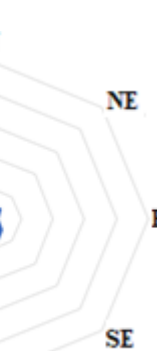

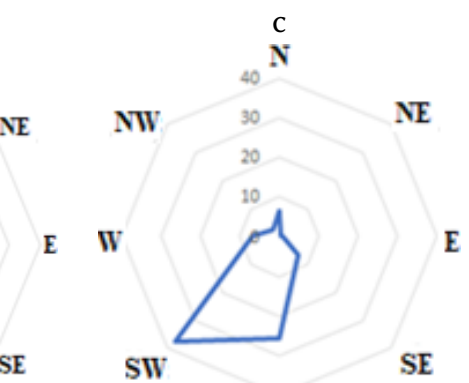

S

Figure 2: Frequency of wind directions (\%) at the Iskitim meteorological station for January (a), February (b) and December (c) 2018.

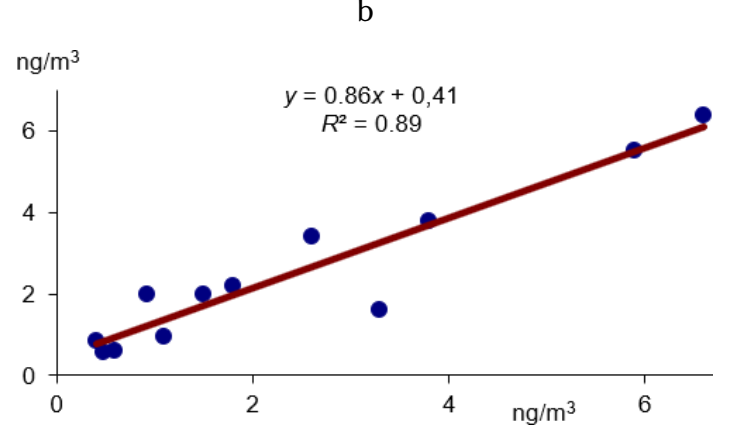

Figure 3: Correlation relationship between average monthly BP concentrations in 2018 (a) and 2019 (b) at post No. 21 in Novosibirsk and post No. 1 in Iskitim.

by the similarity of $\mathrm{BP}$ emission sources. In this case, they are large highways located near the observation posts and oriented in the direction from north to south. A certain role is played by the uniformity of meteorological conditions in the cities under consideration, due to the proximity of their location

Despite the high levels of BP concentrations in 2018, the similarity of atmospheric pollution 
processes in 2018 and 2019 should be noted. This conclusion follows from a comparison of figures $3 \mathrm{a}$ and $3 \mathrm{~b}$. The high level of correlation between the data of the BP observations at the stations under consideration makes it possible to carry out additional control of the obtained experimental information. In this regard, a noticeable deviation of one of the points from the correlation dependence (Figure 3, b) indicates the need to clarify the reasons for such a discrepancy.

\section{Conclusions}

The results of the studies made it possible to reveal the relationship between the frequency of calm and increased levels of BP in the atmosphere of the cities of Novosibirsk and Iskitim for the winter period of 2018. The relationship between the frequency of wind directions on BP concentration in the winter months of 2018 turned out to be uncertain.

Using the measurement data carried out in 2018 and 2019, statistical relationships were established between the monthly mean BP concentrations at the observation posts in the cities of Novosibirsk and Iskitim. For these years, the obtained correlation coefficients turned out to be more than 0.94 . The high level of correlations between the measurement data at the posts makes it possible to carry out mutual control of the monitoring data of atmospheric air pollution in the cities under consideration.

To obtain an objective picture of urban air pollution, it is necessary to have a dense observation network. It is also advisable to use various natural tablets. In particular, to attract data from satellite and ground monitoring of snow cover pollution.

\section{Acknowledgments}

The work was carried out within the framework of the State Assignment for the ICM\&MG SB RAS (project 0215-2021-0003), with the financial support of the Russian Foundation for Basic Research and the Government of the Novosibirsk Region (project No. 19-47-540008).

\section{References}

[1] Bezuglaya E.Yu., Smirnova I.V. Air of cities and its changes. St. Petersburg: Asterion, 2008.

[2] Bezuglaya E.Yu. Monitoring of the state of air pollution in cities. Leningrad: Gidrometeoizdat, 1986.

[3] Byzova N.L., Garger E.K., Ivanov V.N. Experimental studies of atmospheric diffusion and calculations of impurity scattering. Leningrad: Gidrometeoizdat, 1991.

[4] Berlyand M.E. Modern problems of atmospheric diffusion and atmospheric pollution. Leningrad: Gidrometeoizdat, 1975.

[5] Methodological recommendations for assessing the degree of atmospheric air pollution in settlements with metals according to their content in the snow cover and soil. Moscow: IMGRE, 1990.

[6] Vasilenko V.N., Nazarov I.M., Fridman Sh.D. Monitoring of snow cover pollution: monograph. Leningrad: Gidrometioizdat, 1985. 
[7] Yusupov D.V., Rikhvanov L.P., Baranovskaya N.V., Yalaltdinova A.R., Geochemical features of the elemental composition of poplar leaves in urbanized areas // Izv. Tomsk Polytechnic University. Engineering of Georesources. 2016. Vol. 327. No. 6. P. 25-36.

[8] Dmitriev A.V., Dmitriev V.V. Theoretical and experimental study of the processes of snow cover melting in the region of Omsk based on materials from 2008-2009// Modern Problems of Remote Sensing of the Earth from Space. 2010. Vol. 7. No. 2. P. 138-148.

[9] Raputa V.F., Kokovkin V.V., Morozov S.V., Yaroslavtseva T.V. Organic carbon in the city territories of the south of West Siberia // Chemistry for Sustainable Development. 2016. Vol. 24. P. 483-489.

[10] Bortnikova S.B., Raputa V.F., Devyatova A.Yu., Yudakhin F.N. Methods for analyzing data on snow cover pollution in the zones of influence of industrial enterprises // Geoecology. Engineering geology. Hydrogeology. Geocryology. 2009. No. 5. P. 447-457.

[11] Dmitriev A.V., Dmitriev V.V. Tracking the correlation of the NDVI dynamics in comparison with the aerosol fallout zone // Modern Problems of Remote Sensing of the Earth from Space. 2008. Vol. 1. No. 5. P. 92-95.

[12] Polishchuk Yu.M., Khamedov V.A., Rusakova V.V. Remote studies of the impact of associated gas flaring on the forest cover of an oil-producing area using the vegetation index // Modern Problems of Remote Sensing of the Earth from Space. 2016. Vol. 13. No. 1. P. 61-69.

[13] Vasilevich M.I., Elsakov V.V., Shchanov V.M. Application of satellite research methods in monitoring the state of forest phytocenoses in the emission zone of an industrial enterprise // Modern Problems of Remote Sensing of the Earth from Space. 2014. Vol. 11. No. 1. P. 30-42.

[14] Kurbanov E.A., Vorobiev O.N., Lezhnin S.A., Polevshchikova Yu.A. Assessment of forest stands pollution with silicate production waste based on RapidEye image // Modern Problems of Remote Sensing of the Earth from Space. 2013. Vol. 10. No. 2. P. 88-97.

[15] Riggs G., Hall D., Salomonson V. A snow index for the Landsat thematic mapper and moderate resolution imaging spectrometer // Geoscience and Remote Sensing Symposium, IGARSS'94. 1994. Vol. 4: Surface and Atmospheric Remote Sensing: Technologies, Data Analysis, and Interpretation. P. 1942-1944.

[16] Bezuglaya E.Yu., Rastorgueva G.P., Smirnova I.V. What the industrial city breathes. Leningrad: Gidrometeoizdat, 1991.

[17] Selegey T.S. Formation of the level of air pollution in the cities of Siberia. Novosibirsk: Nauka, 2005.

[18] Raputa V.F., Lezhenin A.A. Analysis of the processes of long-term pollution of the atmosphere of Iskitim // Interexpo Geo-Siberia. 2020. Vol. 4. No. 1. P. 137-141.

[19] Luchitskaya I.O., Belaya N.I., Arbuzov S.A. Climate of Novosibirsk and its changes. Novosibirsk: Publishing house of the SB RAS, 2014. 